\title{
THE IMPORTANCE AND PREVENTION OF OEDEMA OF THE HAND
}

\author{
T. L. Barclay, F.R.C.S.(ED.) \\ Plastic Surgeon, Pinderfields Hospital, Wakefield
}

CEDEMA of the hand may follow severe trauma, or operations, and will cause delay in return of function, if it is allowed to persist. Other conditions, such as Sudeck's atrophy and arthritis, may also result in stiffness, but delayed resolution of œdema is the commonest.

It follows that hand function will return more quickly and less time will be lost from work, if œdema consequent upon injury or operation can be minimized. A manual worker needs a powerful grip if he is to do his job with efficiency and safety, and it is useless to expect a labourer to return to work until he has recovered a satisfactory range of pain-free movement.

It is therefore profitable to consider the common causes of post-operative œdema, and hence the measures which will be the most effective in its prevention.

\section{Causes}

The common causes of œdema are:

\section{Infection.}

Any local infection is accompanied by œdema.

\section{Trauma.}

Some degree of œedema will result from any injury, surgical or accidental, however small. It seems probable that the actual amount of odema will depend on three interrelated factors-the degree of trauma, the physique of the patient, and the length of time during which the hand is allowed to be dependent in the absence of function.

A consideration of these factors affecting a series of patients undergoing surgery for Dupuytren's contracture was reported by Barclay (1959). It appeared that there was a correlation between the patient's physique and the amount of swelling which could be detected by plethysmography three weeks later (i.e. when the dressings were removed); the fatter (more endomorphic) the patient, the more œdema would there be. Again, more swelling could be detected in patients who had undergone a radical fasciectomy than in those in whom the operation had been strictly localized to the affected finger and the adjacent part of the palm. No correlation was found with such other factors as the length of time the hand was ischæmic as a result of the tourniquet (up to 70 minutes) or to the type of dressing used. This work is so far unconfirmed, but most surgeons who have to deal with hands would agree that fat men with fat hands have more trouble in regaining full function than do thin men with thin hands.

\section{Disuse in dependency}

Tissue fluid collecting under the influence of gravity will not disperse without active movement of the part.

\section{Measures to Reduce CEdema}

The measures which can be taken to minimize œdema are therefore:

\section{Avoidance of infection}

The best safeguard against infection following hand injury is the assurance of a good blood supply. Constricting dressings and bandages, hæmatoma formation giving rise to tension, and suturing a wound with skin loss by dragging the edges together must all be avoided. The administration of antibiotics may be indicated if the wound were sustained under conditions which made sepsis a particular hazard, or when treatment has been delayed (see 5 below), but attention to basic surgical principles is usually far more important.

\section{Avoidance of extra trauma}

The greatest gentleness in handling tissues, reducing and immobilizing fractures and in bandaging should be used.

\section{Avoidance of unnecessary dissection}

Operations for hand conditions such as Dupuytren's contracture, tendon grafts and tendon transfers should be designed to avoid unnecessary dissection of tissue planes; the relevant structures only should be properly and gently exposed.

\section{Avoidance of hamatoma}

Hæmatoma formation, apart from its own risks, induces surrounding œdema; hæmostasis is therefore most important. At the completion of the procedure the dressing must be designed to exert mild, even pressure over the whole area which has been operated on (unless continuous suction drainage is being used). It is of cardinal importance to avoid tight crêpe bandages, firstly because lateral compression of the hand allows a pool of blood to collect in the hollow of the palm, and secondly because it is not unknown for pressure 


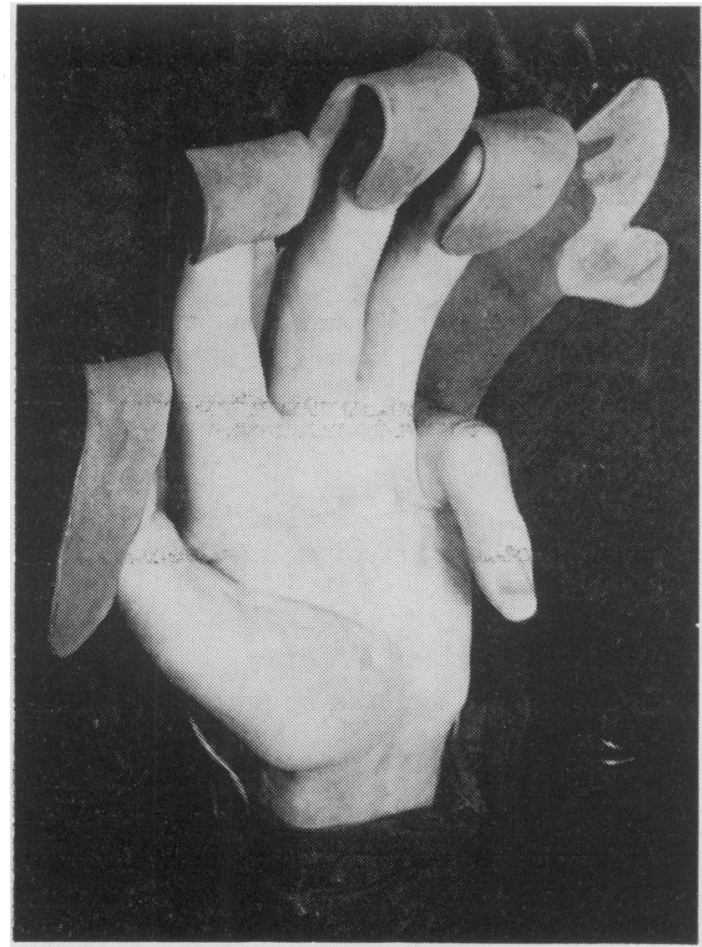

FIG. I.-Adsanced localized Dupuytren's contracture L.fore opidion.

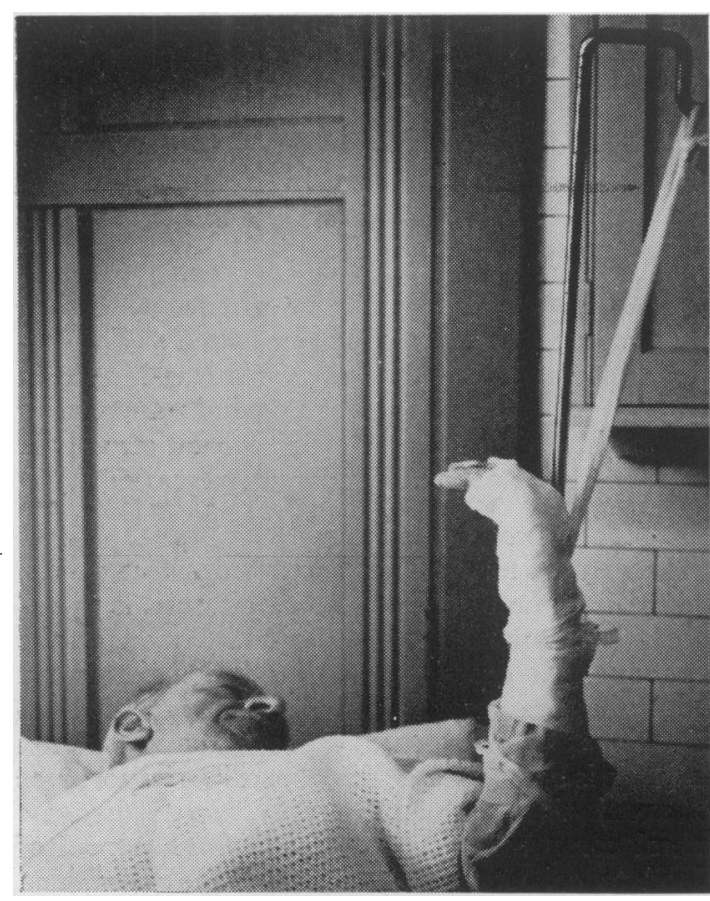

Fig. 3.-Hand elevated for return journey to ward.

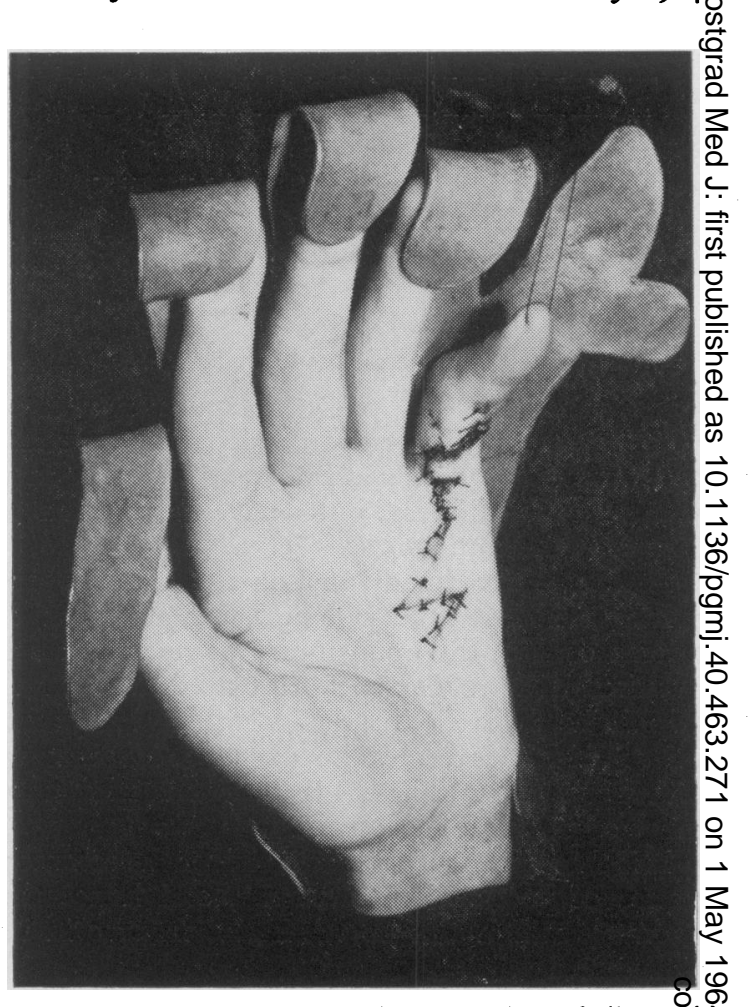

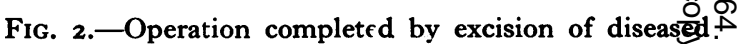
tissue through longitudinal incision and closure with Z-plasties.

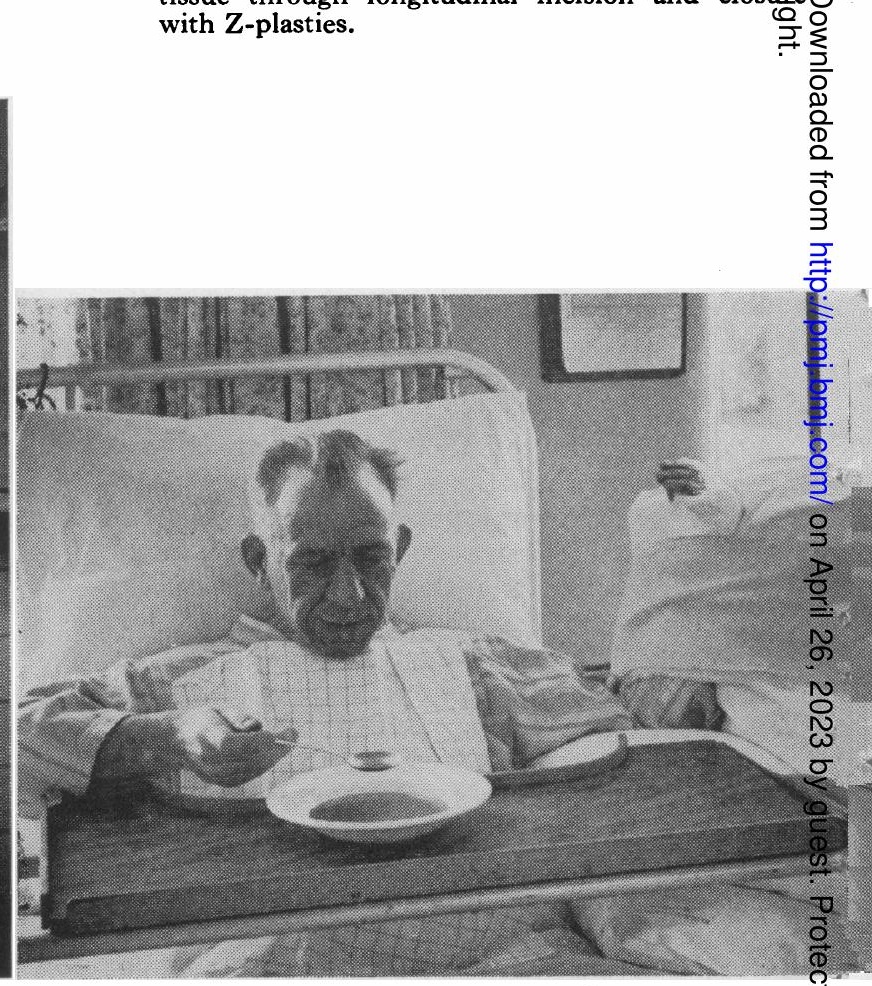

Fig. 4.-Elevation of hand continued for 48 hours. $\stackrel{\mathcal{Q}}{\mathbb{Q}}$ 


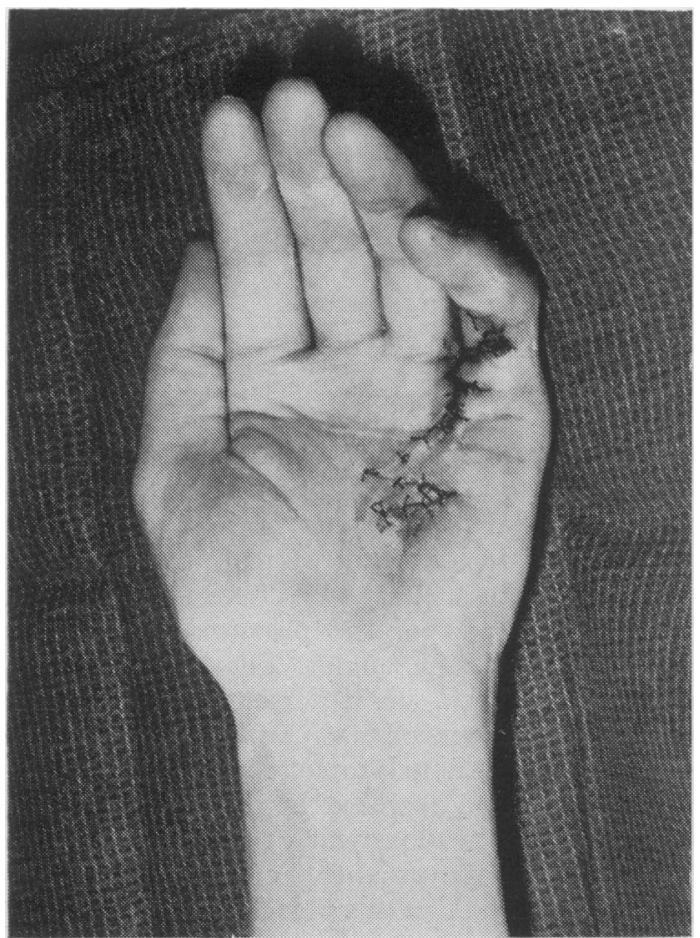

Fig. 5.-Dressings remored on fifth day and replaced by protective dressing allowing some movement. Note minimal swelling. Patient allowed home.

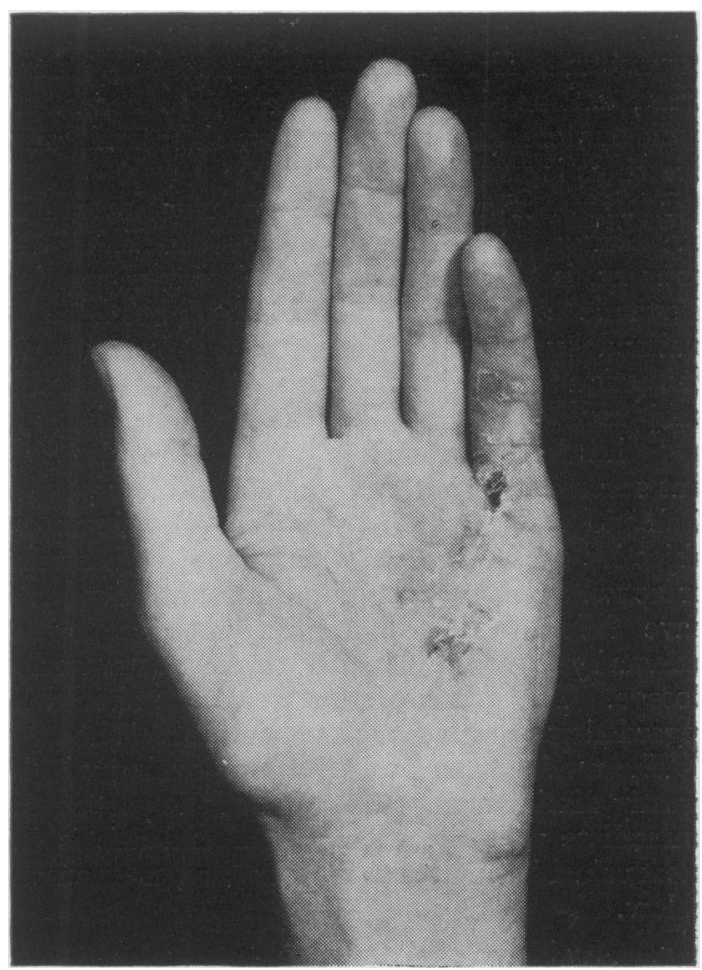

Fig. 6.

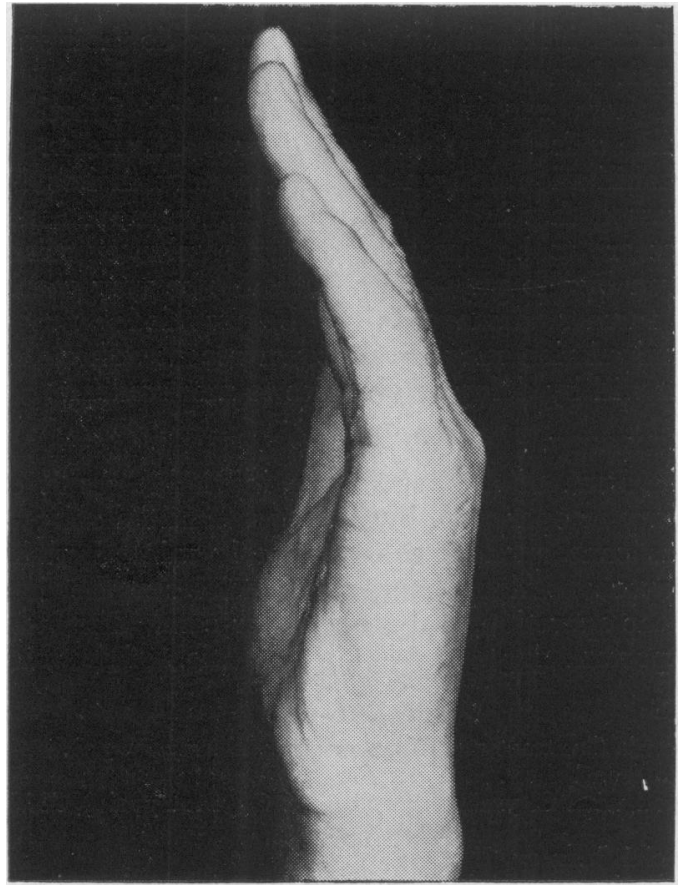

Fig. 7.

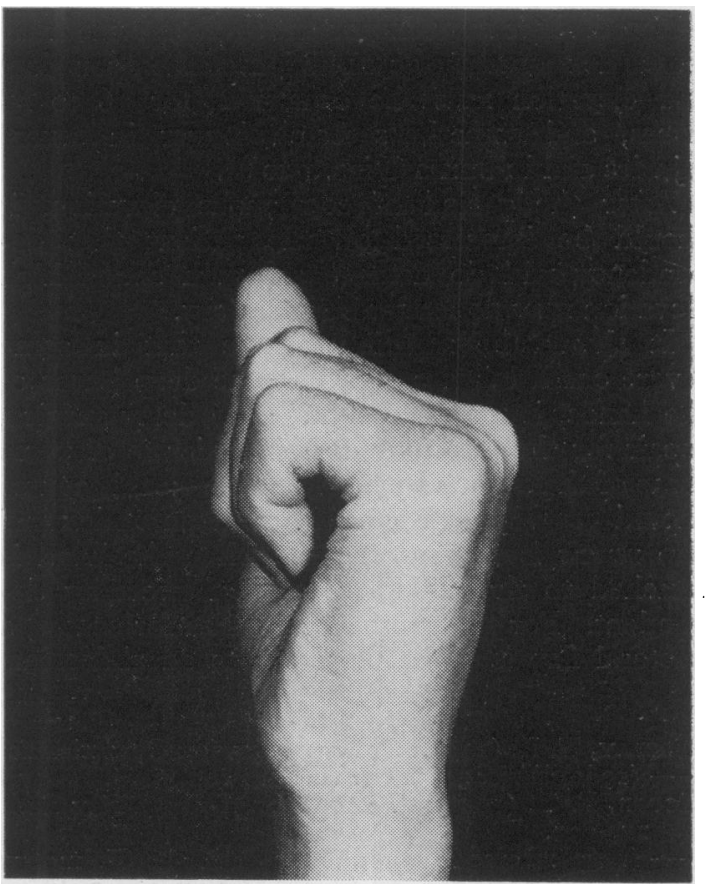

Fig. 8.

FIGS. 6, 7, 8.- Sixteenth day, following removal of sutures. Almost full extension and flexion has been regained. N.B.-This is a favourable case: a thin patient, a localized disease, and proper facilities for surgery and after-care. 
necrosis of the thenar or hypothenar muscles to occur if constriction is extreme; ischæmic contractures of this kind are extremely difficult to treat, and must never be allowed to occur. A judicious combination of plaster slabs and gauze dressings is usually best.

Mention of anti-inflammatory enzymes can be made here. The best known of these, in this country, is 'Chymar' (lyophilized chymotrypsin). Systemic administration of this substance is claimed by the manufacturers to reduce œdema formation following trauma. A favourable subjective assessment, based on clinical impression, has been reported by Moore (1959, 1963), but several other authors (Calnan and Barr, 1960; Gall and Talbot, 1962; Barclay, r960), using more objective methods such as the double-blind trial, or actual measurement of the amount of œdema, have failed to find a significant reduction of œedema by the use of 'Chymar' in the recommended dosage. The status of this treatment should be regarded at the present time as unestablished.

The tendency to post-operative oozing will be greatly diminished by elevation of the part in the immediate post-operative period, and this is the most valuable single step in after-care, as discussed below.

\section{Avoidance of dependency}

The hand should not be allowed to be dependent until a reasonable degree of function has been restored. It is most important to elevate the hand from the moment of completion of the operation, and elevation must be continued for 36 to 48 hours, and sometimes much longer in severe injuries and in burns (Figs. 1 to 8 ).

After the period of continuous elevation, it should be impressed on the patient that dependency will do damage although actual high elevation may no longer be necessary.

It should be mentioned here that in some severe crush injuries, and in some deep burns of the hands, it may be profitable to delay surgical repair for three to four days in order to disperse some of the œdema by high elevation; this course should especially be considered if an abdominal flap repair is necessary, since when the hand is attached to the abdomen it is of necessity dependent. For this reason, as well as for others, a pectoral flap is to be preferred to an abdominal flap if the size and situation of the wound on the hand permit, since partial elevation will thus be achieved. Should the surgeon decide to delay the repair by reason of gross œdema, a course of antibiotics should be started from the outset. It ${ }_{c}$ is most unwise to withhold the repair for more than five days as infection will certainly supervene despite precautions, and may convert a severe injury into an irreparable one.

\section{Avoidance of faulty immobilization}

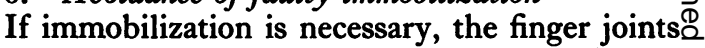
should be held in such a position that even if some stiffness does develop the collateral ligaments arenot allowed to shorten. The best position for the metacarpo-phalangeal joints is in about $80^{\circ}$ of $\vec{\omega}$ flexion, as the attachments of the collateral ligaments to the distal part of the metacarpal ando the proximal part of the proximal phalanx are furthest apart at this angle. The interphalangeal $f$ joints should be in slight flexion only. In burns of the hands it is particularly important to achieve this position both to protect the ligaments from $Y$ shortening and to decrease the danger of exposure ${ }_{\circ}^{-}$ of the extensor tendon which tends to occur over? the dorsum of the proximal interphalangeal joint ${ }_{\vec{z}}^{-}$ if flexion is allowed at this point.

7. Avoidance of faulty physiotherapy hands will, if properly cared for, have litfe stiffness following even quite extensive injuries, and can, if intelligent, be relied on to do their own physiotherapy.

Others require help in regaining function. While this is not the place for a discussion of rehabilitation in general, it can nevertheless $b_{\stackrel{\circ}{\vec{O}}}^{\overrightarrow{0}}$ stressed that in the main it is active movements 3 that are to be encouraged and passive exercises? given by the physiotherapist must be very gentle? if further damage is to be avoided; rougho manipulation may break down recent adhesions, but will by doing so give rise to more œdema.

\section{Summary}

Edema of the hand is an inevitable result of injury or operation, but its degree and its deleter-윽 ious consequences can be greatly minimized by proper attention to surgical principles at the time of the operation, and proper after-care. The most important single step is high elevation of the part

\section{REFERENCES}

Barclay, T. L. (1959): Edema following Operation for Dupuytren's Contracture, Plast. reconstr. Surg., $23,348$. (1960): Effect of 'Chymar' on Post-operative Swelling of the Hand, Brit. F. plast. Surg., 13, 253.

Moore, F. T. (1959): A Report on Seventy-Five Patients Treated with Chymar (Lyophilized Chymotrypsin), Ibid.s,

II, 335.

Gall, W. J. and TALBOT, C. H. (1962): Chymotrypsin in the Reduction of Post-operative Bruising and CEdema

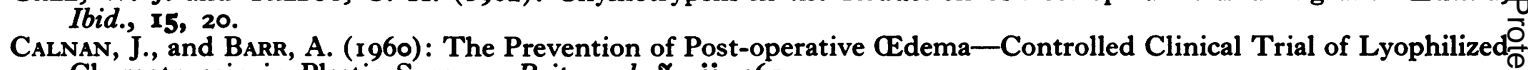
Chymotrypsin in Plastic Surgery, Brit. med. $\mathcal{F}$., ii, $26 \mathrm{I}$. 